\title{
ReFleXões Sobre Uma Ética NA TRADUÇÃo
}

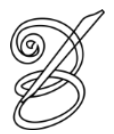 \\ Giovana Bleyer F. dos Santos \\ (Doutoranda - PGET/UFSC) \\ giovanableyer@gmail.com \\ Marie-Hélène C. Torres \\ (Pós-Doutora - UFSC) \\ marie.helene.torres@gmail.com
}

\begin{abstract}
Resumo: Este artigo é fruto da tese de doutorado em andamento intitulada Paul et Virginie: os paratextos em tradução e as traduções brasileiras no século $X X$, que, entre outros objetivos, propõe uma análise diacrônica das sete traduções brasileiras encontradas do romance Paul et Virginie de Bernardin de Saint-Pierre, e uma tradução comentada dos três paratextos que acompanham a obra. Para o desenvolvimento de nossa análise, que segue um princípio pautado em uma ética da tradução, nos baseamos em reflexões de autores como Antoine Berman e Lawrence Venuti. E para validar o uso dos paratextos como um recurso mediador no processo tradutório e na recepção de um texto dentro de um sistema, em Gérard Genette. Dessa maneira, procuraremos apresentar neste artigo as conceituações teóricas que regem parte de nosso horizonte tradutório.
\end{abstract}

Palavras-chave: tradução, ética, paratexto.

Abstract: This paper is the result of an ongoing doctoral thesis entitled: "Paul and Virginie: the Paratexts in Translation and the Brazilian Translations in the Twentieth Century," which among other goals, aims to analyze diachronically the six Brazilian translations found of the novel "Paul et Virginie" written by Bernardin SaintPierre, and a commented translation of the three paratexts that follow the work. Moreover, to develop our analysis that adopts a principle ruled by the translation ethics, we rely on the reflections from some authors, such as, Antoine Berman and Lawrence Venuti. And also, in order to validate the use of paratexts as a mediator resource in the process of translation and reception of a text within a system, in Gérard Genette. Thus, in this paper, we try to present the theoretical concepts that rule part of our translation horizon.

Keywords: translation, ethics, paratext.

\section{INTRODUÇÃOO}

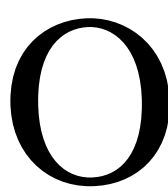
presente artigo tem por objetivo apresentar algumas reflexões de teóricos como Antoine Berman e Lawrence Venuti, que possibilitam a sistematização do processo tradutório por meio de uma abordagem ética. A escolha desses autores deveu-se ao fato de que eles, ao pensarem esse processo, desenvolveram uma metodologia que consiste, entre outras coisas, na realização de um trabalho que respeite as diferenças linguísticoculturais do texto de partida e que veja no crescente reconhecimento da visibilidade do tradutor um caminho para o seu acontecimento. Pensando ainda em meios para viabilizar o desenvolvimento dessa abordagem, incorporamos aos princípios que regem esse horizonte 
tradutório a estratégia da escritura de paratextos. Acreditamos que esse recurso pode funcionar como um mecanismo de mediação entre o texto de partida e o texto de chegada situando no novo sistema: o autor, a sua obra e algumas peculiaridades que os caracterizam. Para tratarmos desse assunto referente ao paratextos, escolhemos o autor Gérard Genette, que discorreu detalhadamente sobre diferentes tipos de paratexto e suas funções na obra Seuils (1987), traduzida no Brasil como Paratextos editoriais (2009).

\section{A TRADUÇÃO E SEU PRINCÍPIO ÉTICO}

Antoine Berman (2007), em suas considerações sobre a essência última e definitiva da tradução, nos diz que "a tradução é tradução-da-letra, do texto enquanto letra" (ibidem, p. 26) e destaca três traços que definem a tradução: quando falamos culturalmente, ela é etnocêntrica; quando falamos literariamente, ela é hipertextual; e quando falamos filosoficamente, ela é platônica. A essência desses três traços oculta, para Berman (2007), uma essência mais profunda que é "simultaneamente ética, poética e pensante" e que se define "em relação ao que chamamos a letra" (ibidem, p.26).

Ele nos fala ainda que a tradução é um processo de comunicação e, de certa forma, de "introdução" (BERMAN, 2007, p. 65), visto que ela possibilita que o leitor de chegada tenha contato com um texto que ele não poderia conhecer em outras circunstâncias. Nesse contexto, em que o tradutor procura viabilizar o contato do leitor com a tradução, Berman (2007) destaca duas palavras que para ele estão cheias de sentido e história e que de certa forma regem o objetivo ético da tradução: a fidelidade e a exatidão. Afirma que essas palavras "se referem a uma certa postura do homem em relação a si mesmo, aos outros, ao mundo e à existência. E, do mesmo modo, certamente, em relação aos textos" (ibidem, p. 67), pois "fidelidade e exatidão se reportam à literalidade carnal do texto" (ibidem, p. 70).

Ao reafirmar que a tradução, com seu objetivo de fidelidade, "pertence originalmente à dimensão ética" (BERMAN, 2007, p. 69), argumenta que ela, em sua essência, é animada pelo desejo de "abrir o Estrangeiro enquanto Estrangeiro ao seu próprio espaço de língua". Ou seja, de "reconhecer e receber o Outro enquanto Outro [...] acolher o Outro, o Estrangeiro, em vez de rejeitá-lo ou de tentar dominá-lo", de maneira que "o objetivo ético, poético e filosófico da tradução consiste em manifestar na sua língua esta pura novidade ao preservar sua carga de novidade" (ibidem, p. 69).

Nesse contexto, entram em jogo dois focos de mediação: a figura do tradutor, cuja visibilidade e posição tradutória tem sido cada vez mais reconhecida e estudada; e a escritura 
dos paratextos. Acreditamos que se houver um equilíbrio entre estes dois focos, a estrangeiridade dos textos traduzidos será mais facilmente mantida.

Para discutir um pouco sobre a visibilidade do tradutor, tomaremos como ponto de partida o teórico americano Lawrence Venuti.

Venuti (1995, p. 6-7) destaca que ao se falar de tradução, nos colocamos diante de dois dilemas,

\begin{abstract}
de um lado, a tradução é definida como uma representação de segunda ordem: apenas o texto estrangeiro pode ser original, uma autêntica cópia, fiel à personalidade ou intenção do autor, enquanto a tradução é derivativa, falsa, potencialmente uma falsa cópia. Por outro lado, é necessário à tradução um discurso transparente para apagar o status de segunda-ordem, produzindo a ilusão de uma presença autoral através da qual o texto pode ser tomado como o original. ${ }^{1}$
\end{abstract}

Para o autor, esses posicionamentos levam a três questionamentos, o da invisibilidade do tradutor, o da domesticação e o da estrangeirização textual.

A questão da invisibilidade do tradutor pode ser discutida tomando como exemplo a própria domesticação textual. Se depararmos, por exemplo, com um texto "transparente" que apresenta uma leitura "fluida", podemos, na maioria dos casos, verificar que há também a invisibilidade do tradutor. Isto porque um texto traduzido que não cause um estranhamento no leitor de chegada pode esconder a diferença linguístico-cultural existente entre os textos e entre os respectivos leitores. É claro que não desconsideramos que o próprio Venuti (2002) comenta que "as traduções [...] inevitavelmente realizam um trabalho de domesticação" (ibidem, p. 17). Contudo, o que é importante mencionarmos aqui é que essa visão do autor não o impede de considerar que um trabalho de domesticação que deixe o discurso "transparente" pode ocasionar a destruição da letra. E essa destruição da letra coloca em discussão novamente a questão da ética da tradução, que, assim como foi mencionada por Berman (2007), também o é por Venuti (2002).

Venuti (2002, p. 19) faz menção ao fato de que a tradução levanta questões éticas que devem ser averiguadas, afirmando que a ética da tradução

\footnotetext{
deve ser teorizada como contingente, um ideal baseado em situações culturais específicas nas quais os textos estrangeiros são escolhidos e traduzidos ou nas quais as traduções e o ato de traduzir são feitos objetos de pesquisa.
}

Em sua postura ética, advoga que "as traduções sejam escritas, lidas e avaliadas com maior respeito em relação às diferenças linguísticas e culturais” (ibidem, p. 20), pois em uma tradução, essas diferenças devem ser negociadas. Para ilustrar esses pensamentos do autor, 
podemos fazer uma breve revisão da literatura apresentada por ele em The Translator's Invisibility: A History of Translation (1997) A invisibilidade do tradutor.

Procurando talvez uma forma de caracterizar a ética da tradução, Venuti (1997) retoma o teórico alemão Friedrich Schleiermacher e diz que na visão de Scheleiermacher (apud VENUTI, 1997, p.19-20) o tradutor possuía apenas dois caminhos: " "Ou o tradutor deixa o autor em paz, tanto quanto possível, e aproxima o leitor dele; ou ele deixa o leitor em paz, tanto quanto possível, e aproxima o autor dele".

Considerando ainda que não é possível que o tradutor se adéque completamente ao texto estrangeiro, Schleiermacher afirma que é necessário que ele escolha entre o método domesticante e o método estrangeirizante. Para esse teórico, caso o tradutor opte pela domesticação, estará "trazendo o autor para casa"3 (VENUTI, 1997, p. 20), visto que haverá uma redução etnocêntrica do texto estrangeiro no que diz respeito aos valores culturais da língua de chegada. E, se escolher a estrangeirização, o autor fará um movimento contrário, de levar "o leitor para fora"4 devido às diferenças linguísticas e culturais do texto (ibidem, p. 20).

Para Venuti (1997), Schleiermacher deixa claro que sua opção é a tradução 10 estrangeirizante e foi essa ilustração feita pelo crítico que, segundo Venuti (1997), levou o teórico Antoine Berman a considerar esse posicionamento de Schleiermacher como uma ética da tradução. Isso, porque como coloca Venuti (1997), Berman vê o texto traduzido como um lugar onde a cultura do outro é manifestada, ainda que essa manifestação só possa ocorrer nos termos da própria cultura de chegada.

Nesse ponto, é importante ressaltar que Venuti (1997, p. 20) já formula sua conceituação de que o "estrangeiro" na tradução estrangeirizante,

não é uma representação transparente de uma essência que reside no texto estrangeiro e é válido em si, mas uma construção estratégica cujo valor depende da situação da língua de chegada. Tradução estrangeirizante significa a diferença do texto estrangeiro, mas apenas rompendo o código cultural que prevalece na língua de chegada. ${ }^{5}$

Essa questão pode nos levar de volta à discussão sobre a invisibilidade do tradutor. Embora muitos leitores ainda vejam a invisibilidade do tradutor como um indicativo de boa leitura, é notável que o papel crucial que ele desenvolve tem sido mais reconhecido desde os anos 1980. Podemos comprovar isso tanto pelas referências feitas a ele como "autor" ou "tradutor" de determinado texto, quanto pela indicação de seus direitos autorais manifestados pelo seu nome no texto, como destaca Venuti (1997). 
Paralelo a isso, temos também a opinião de Susan Bassnett (2003, p. 9), que, ao falar sobre o modo como a tradução é vista hoje no cenário mundial, acaba por reafirmar o valor que deve ser atribuído ao tradutor:

A tradução não é somente a transferência de textos de uma língua para outra - ela é hoje corretamente vista como um processo de negociação entre textos e entre culturas, um processo em que ocorrem todos os tipos de transações mediadas pela figura do tradutor.

Bassnett (2003) mostra mais uma confirmação da importância que deve ser atribuída ao tradutor e do caráter heterogêneo das línguas-culturas envolvidas em um processo tradutório.

Dessa maneira, retomando os conceitos por que passamos rapidamente, podemos extrair os seguintes caracteres gerais: a tradução é um processo de negociação entre línguasculturas, em que o tradutor é o agente responsável pelo trabalho mediador que permite que os leitores de chegada tenham acesso ao texto de partida; ela é culturalmente etnocêntrica, como ressalta Berman (2007), pois traz consigo elementos específicos de um tempo, de um espaço, de uma cultura determinada; como a representação desta língua-cultura de partida é feita utilizando-se elementos da língua-cultura de chegada, ela indiscutivelmente passa por um processo de domesticação; contudo, sabendo-se da importância de se manter uma ética da tradução, o tradutor que agora tem sua visibilidade legitimada, deve procurar em seu processo de mediação "reconhecer e receber o Outro enquanto Outro [...] acolher o Outro, o Estrangeiro, em vez de rejeitá-lo ou de tentar dominá-lo" (BERMAN, 2007, p. 69). E, considerando-se ainda, como vimos em Berman (2007), que a tradução é um processo de comunicação e, de certa forma, de "introdução, cujo objetivo ético, poético e filosófico consiste em manifestar no texto de chegada essa 'pura novidade' (Ibidem, p. 69)" advinda do texto de partida, o tradutor pode optar por paratextos como recurso auxiliar a esta mediação.

Vejamos a seguir com um pouco mais de detalhe o que são os paratextos na visão de Gérard Genette, e como eles já ocupavam um lugar determinado no sistema literário desde épocas remotas.

\section{A CONSTRUÇÃO PARATEXTUAL}

Gérard Genette, em sua obra Paratextos Editoriais (2009), inicia suas considerações relembrando que, em se tratando de uma obra literária, o texto raramente se apresenta sem "o acompanhamento de certo número de produções", que são os chamados "paratextos". Eles cercam e prolongam o texto literário para "apresentá-lo, no sentido habitual do verbo, mas 
também em seu sentido mais forte: para torná-lo presente, para garantir sua presença no mundo, sua recepção" (GENETTE, 2009, p. 9).

O autor ainda menciona que mesmo na Antiguidade e na Idade Média, "época em que os textos circulavam muitas vezes em estado quase bruto, sob a forma de manuscritos desprovidos de qualquer fórmula de apresentação" (ibidem, p. 11), já podemos considerar que havia paratextos. Isso porque a transcrição e a transmissão oral existentes naquela época eram uma forma de introduzir na idealidade do texto uma materialização, gráfica ou fônica, que poderia induzir efeitos paratextuais. Nesse sentido, Genette $(2009$, p. 11) coloca que sem dúvida "não existe e jamais existiu um texto sem paratexto". 6

Paradoxalmente, o autor menciona ainda que, "há em contrapartida, talvez por acidente, paratextos sem texto, pois existem muitas obras desaparecidas ou abortadas, das quais conhecemos apenas o título" (GENETTE, 2009, p. 11), como é o caso citado por ele de, Bataille des Termopyles, um dos projetos abandonados de Flaubert.

Sobre a condição pragmática de um elemento de paratexto, o autor nos diz que ela é definida basicamente "pelas características de sua instância, ou situação de comunicação: 12 natureza do destinador, do destinatário, grau de autoridade e de responsabilidade do primeiro, força ilocutória de sua mensagem" (GENETTE, 2009, p. 15). Ele ainda destaca que no caso do destinador, ele é "definido por uma atribuição putativa e por uma responsabilidade assumida" (ibidem, p. 15), já que o destinador não é necessariamente o autor do paratexto. Já em relação ao destinatário, ele nos diz que, embora certos elementos de paratextos, como os títulos, por exemplo, se dirijam ao público em geral, outros se dirigem especificamente apenas aos leitores do texto, como é o caso dos paratextos que nos interessam particularmente para este estudo, a saber, o prefácio e as notas.

Diferentemente do título e do nome do autor, que, segundo Genette (2009) são praticamente indispensáveis nos dias de hoje, o prefácio, definido por ele como "toda espécie de texto liminar (preliminar ou pós-liminar), autoral ou alógrafo, ${ }^{7}$ que consiste num discurso produzido a propósito do texto que segue ou antecede (ibidem, p. 145), não é obrigatório.

O prefácio, cuja maioria dos temas e procedimentos já existiam desde meados do século XVI, como nos diz o teórico, é lido pelo "dono do livro", ele "postula de seu leitor uma leitura eminente ou mesmo (posfácio) anterior à do texto" (GENETTE, 2009, p. 172-173). Sendo assim, é possível concluirmos que um prefácio de tradução, por exemplo, se torna de fato um espaço propício para o tradutor dialogar com o leitor do texto de chegada. Ele pode situar melhor esse leitor no contexto histórico-cultural do autor e dos leitores do texto de 
partida, explicar alguns termos específicos que caracterizem esse universo específico em que o texto foi criado e mesmo justificar algumas escolhas que tiverem que ser feitas no decorrer do processo tradutório.

Em posição semelhante, temos também o paratexto "nota", denominado por Genette (2009) como "um enunciado de tamanho variável (basta uma palavra) relativo a um segmento mais ou menos determinado de um texto, e disposto seja em frente seja como referência a esse segmento" (ibidem, p. 281).

Segundo Genette (2009), as notas se dividem em algumas categorias como: originais, autorais, fictícias, etc. A nota, denominada por ele como original, é tida como a nota básica, da qual todas as outras se derivam, e também é dessa nota que os tradutores geralmente fazem uso em seus trabalhos. Em sua composição, podemos deparar com "definições ou explicações de termos usados no texto, às vezes a indicação de um sentido específico ou figurado" (GENETTE, 2009, p. 286).

E visto que "a nota original é um desvio local ou uma bifurcação momentânea do texto" (GENETTE, 2009, p. 289), ela pode efetivamente servir para explicar uma "estrangeiridade" do texto de partida, sem que seja preciso realizar uma domesticação que comprometa a carga de novidade do texto.

Ainda em relação à criação desse paratexto, Genette (2009) destaca uma característica de semelhança entre a nota e o prefácio, que é o fato que ela pode tanto aparecer quanto desaparecer da vida do texto a qualquer momento. Ele também nos fala do destinador da nota, que é, a princípio, certamente o leitor do texto, fato que justifica a própria existência da nota. E reforça essa posição explicitando que há casos em que as notas se endereçam "a apenas alguns leitores: aqueles a quem possa interessar determinada consideração complementar ou digressiva, cujo caráter acessório justifica exatamente a colocação em nota" (ibidem, p. 285), como podemos aferir que seja o caso de notas sobre a tradução.

Para exemplificar rapidamente como esse recurso pode auxiliar na preservação da carga de novidade do texto, apresentamos uma das notas criadas por Rosa Maria Boaventura em sua tradução do romance Paul et Virginie:

Marron - Do espanhol cimarron, isto é, selvagem. Daí passou a significar escravo refugiado nas matas para viver em liberdade. Embora alguns traduzam por quilombos, deixamos o termo em francês por não corresponder exatamente ao sistema dos nossos quilombos ou mocambos, organizados em comunidades fixas, ao passo que os marrons podiam viver isolados. (SAINT-PIERRE, 1986, p. 87) 
A nota citada se refere a uma passagem do romance em que Paul e Virginie ajudam uma escrava, uma "negra marrone", que havia fugido de seu senhor. Ela apareceu faminta na casa das personagens que a alimentaram e a acompanharam para pedir perdão ao seu senhor pela fuga.

Aqui é importante ressaltar que pelas referências bibliográficas indicadas pela tradutora, tomamos conhecimento de que ela consultou uma edição crítica do referido romance, feita por Pierre Trahard, em 1958. Consultando essa edição do romance descobrimos que parte das informações contidas na nota criada por Boaventura era uma tradução de nota criada por Trahard, como a origem do nome. Contudo, percebemos que a tradutora foi além de uma mera tradução e acrescentou elementos que enriqueceram o conhecimento do leitor, como o fato de ter optado por manter o termo em francês, já que não havia um correspondente em português que pudesse traduzir todo o significado pretendido por Saint-Pierre.

\section{CONSIDERAÇÕES FINAIS}

14 Com esta pequena ilustração acreditamos que tenha sido possível demonstrar que a utilização do paratexto pode ser um recurso útil para a manutenção da estrangeiridade do texto e a para a realização de um trabalho ético. Sendo assim, a escritura de paratextos é proposta como um recurso colaborativo na conservação da estrangeiridade do texto de partida em situações em que a falta de equivalentes linguísticos no contexto de chegada poderia, por exemplo, ocasionar a destruição da letra. Além disso, considerando-se que ainda há muito para refletir sobre a tradução e o processo tradutório, o paratexto pode também representar um espaço para o tradutor explanar seu horizonte tradutório, de maneira que, um crítico que queira ler e avaliar uma tradução sob uma perspectiva ética, ou seja, respeitando às diferenças linguísticas e culturais envolvidas nesse processo, poderá encontrar respostas para os seus questionamentos na leitura desses paratextos. 


\section{REFERÊNCIAS BIBLIOGRÁFICAS}

BASSNETT, Susan. Estudos de tradução fundamentos de uma disciplina. Tradução Vivina de Campos Figueiredo. Lisboa: Fundação Calouste Gulbenkian, 2003.

BERMAN, Antoine. Bibliothèque des idées por une critique des traductions: John Donne. Paris: Gallimard, 1995.

A tradução e a letra, ou, $\mathbf{O}$ albergue do longínquo. Tradução Marie-Hélène C. Torres, Mauri Furlan e Andréia Guerini. Rio de Janeiro: 7Letras/PGET, 2007.

GENETTE, Gérard. Paratextos editoriais. Tradução de Álvaro Faleiros. Cotia: Ateliê Editorial, 2009.

SAINT-PIERRE, Bernardin. Paul et Virginie. Texte établi avec une introduction, des notes et des variantes par Pierre Trahard. Paris: Classiques Garnier, 1958.

Paulo e Virgínia. Tradução Rosa Maria Boaventura. São Paulo: Ícone, 1986.

VENUTI, Lawrence. The Translator's Invisibility: A History of Translation. London and New York: Routledge, 1997.

Escândalos da Tradução: por uma ética da diferença. Tradução Laureano Pelegrini, Luninéia Marcelino Villela, Marileide Dias Esqueda e Valéria Biondo. Bauru: EDUSC, 2002

1 "on the one hand, translation is defined as a second-order representation: only the foreign text can be original, an authentic copy, true to the author's personality or intention, whereas the translation is derivative, fake, potentially a false copy. On the other hand, translation is required to efface its second-order status with transparent discourse, producing the illusion of authorial presence whereby the translated text can be taken as the original" (p. 6-7).

2 "Either the translator leaves the author in peace, as much as possible, and moves the reader towards him; or he leaves the reader in peace, as much as possible, and moves the author towards him" (apud VENUTI, 1997, p. 19-20).

3 “[...] bringing the author back home" (VENUTI, 1997 p. 20).

4 “[...] sending the reader abroad" (VENUTI, 1997, p. 20).

5 “ $[. .$.$] is not a transparent representation of an essence that resides in the foreign text and is valuable in itself, but$ a strategic construction whose value is contingent on the current targed-language situation. Foreignizing translation signifies the difference of the foreign text, yet only by disrupting the cultural codes that prevail in the targed language" (p. 20).

${ }^{6}$ Digo textos, e não somente obras, no sentido "nobre" da palavra: pois a necessidade de um paratexto impõe-se a toda espécie de livro, mesmo que não tenha nenhuma intenção estética, ainda que nosso estudo se limite aqui ao paratexto das obras literárias.

${ }^{7}$ Para este artigo em específico, nos ativemos apenas as características mais gerais do prefácio sem entrarmos, portanto, em discussões sobre os tipos existentes e suas funções. Aqui, nos focalizamos acima de tudo, na utilidade que ele pode ter para o tradutor enquanto ferramenta auxiliar de mediação textual, que pode permitir a permanência da "estrangeiridade" de um texto de partida, no texto de chegada. 